\title{
Characterization and Comparison of Geopolymer Synthesized Using Metakaolin Bangka and Metastar as Precursors
}

\author{
Sotya Astutiningsih ${ }^{1}$, Dicky Tambun ${ }^{1,}$ and Ahmad Zakiyuddin ${ }^{1 *}$ \\ ${ }^{1}$ Department of Metallurgical and Materials Engineering, Faculty of Engineering, Universitas Indonesia, Depok 16424, Indonesia
}

\begin{abstract}
vAbstract. Various aluminosilicate material have been used as precursor for geopolymer. Geopolymer gets its strength from the polycondensation of silicate and alumina. Metakaolin, calcinated kaolin, is pozzolan with the highest alumina and silicate purity. Indonesia, especially Bangka Island, has a large amount of kaolin deposit that being sold at low price. This price could be increased ten times when being sold as metakaolin. This study aimed to compare mechanical and metallurgical properties of commercial metakaolin and Bangka kaolin which calcinated at $700^{\circ} \mathrm{C}$. Both metakaolins reacted with $\mathrm{NaOH}$ and waterglass as the activator followed by curing at room temperature for 7,14 and 28 days and elevated temperature of $60^{\circ} \mathrm{C}$ for 4,12 and 24 hours. Mechanical properties will be examined by compressive strength and flexural strength test, while the metallurgical properties will be evaluated with SEM, and TAM. The results of the mechanical test will be used to determine which geopolymer will perform well with the microstructure and thermal activity to support the finding. These attempts will be done in order to improve the properties of Bangka metakaolin geopolymer superior to commercial metakaolin.
\end{abstract}

\section{Introduction}

Geopolymers first introduced in the late seventies of the 20th century by Joseph Davidovits [1] who defined geopolymer as a class of cementitious aluminosilicate binder materials synthesized by a geopolymerization reaction of aluminosilicate with alkali activator. Geopolymers considered replacing the traditional structural material by reason of their excellent properties and high performance. The traditional structural material such as Portland cement also bad for the environment as the cement industry itself contributed for $5-8 \%$ of $\mathrm{CO}_{2}$ gas emission globally [2].

Aluminosilicate consists of mostly silicate $\left(\mathrm{SiO}_{2}\right)$ and alumina $\left(\mathrm{Al}_{2} \mathrm{O}_{3}\right)$. They are the most abundant mineral in the earth crust. Aluminosilicate was formed when $\mathrm{Si}^{4+}$ ion replaced by $\mathrm{Al}^{3+}$. For every $\mathrm{Si}^{4+}$ replaced by $\mathrm{Al}^{3+}$, it needs positive ion like $\mathrm{Na}+, \mathrm{K}+$ and $\mathrm{Ca}^{2+}$ to balance the mineral. Hence, in order to synthesize geopolymer, aluminosilicate activated with alkali metals. However, the two most used alkali metal manufacturing geopolymer is sodium and potassium ions. When aluminosilicate reacted with alkali ion, aluminosilicate will rapidly dissolve and free $\left[\mathrm{SiO}_{4}\right]^{-}$ and $\left[\mathrm{AlO}_{4}\right]^{-}$tetrahedral units. This is called the dissolution phase. Then, the tetrahedral units are linked by sharing oxygen atoms to create polymeric $\mathrm{Si}-\mathrm{O}-\mathrm{Al}-$ $\mathrm{O}$ bond [3].
Curing has an essential effect on hardening of geopolymer. B Mo et al [4] studied the effect of curing temperature $\left(20,40,60,80,100^{\circ} \mathrm{C}\right)$ on geopolymer mechanical strength. It was found that the highest compressive strength was reached at $60^{\circ} \mathrm{C}$. The result showed that elevating the curing temperature will accelerate the strength development. The final strength of the geopolymer determined not only by curing temperature but also curing time. Rovnanik [5] showed that geopolymer at elevated temperature has higher early strength. Geopolymer at lower curing temperature with slower geopolymerization will develop strength and eventually have slightly higher strength at 28th day.

In nature, aluminosilicate mineral can be found in various parts of the world. Fortunately, Indonesia especially Bangka and Belitung Islands has a great amount of aluminosilicate mineral known as kaolin. In total, Indonesia has a number of resources amounted to 1414.69 million tons of kaolin [6]. This kaolin was used as raw material for paper, paint and porcelain which is valued at a low price. This price could be increased ten times when being sold as metakaolin.

Metakaolin was obtained by calcinating the kaolin. Calcination is a reaction of decomposition of kaolinite crystals to an amorphous and reactive structure[7]. This new phase called metakaolinite. Unlike kaolin, metakaolinite will be easily activated by alkaline ion.

*corresponding author. E-mail: zakiyuddin@metal.ui.ac.id, Tel. +62-21-7872350. 
Calcination reaction of $700^{\circ} \mathrm{C}$ was chosen based on previous study that suggest metakaolin Bangka has higher amorphous degree than any temperature given.

This research introduces a comparative study between commercial metakaolin and metakaolin Bangka. Through this comparison, we aim to achieve two objectives: first to compare mechanical and metallurgical properties of geopolymer based on the two metakaolin, and second to increase the value of kaolin Bangka commercially.

\section{Experimental}

\subsection{Material}

Metakaolin Bangka was obtained by calcinating milled kaolin Bangka at $700^{\circ} \mathrm{C}$ for 4 hours. Before calcination, kaolin has been milled with 20 rad per minute rate for 20 minutes. The chemical composition of kaolin shown in Table 1. Commercial metakaolin with trade name Metastar was purchased from IMERYS, UK. Metastar was dried at $60 \mathrm{oC}$ for 24 hours to reduce the moisture.

Sodium hydroxide and waterglass $\left(\mathrm{Na}_{2} \mathrm{SiO}_{3}\right)$ was purchased from MERCK, Germany. Alkaline silicate solution was prepared by dissolving of solid sodium hydroxide in waterglass and wait for 24 hours. The water then added before mixing with the metakaolin.

Table 1. Composition of kaolin Bangka.

\begin{tabular}{lllll}
\hline Composition & $\mathbf{S i O}_{\mathbf{2}}$ & $\mathbf{A l}_{\mathbf{2}} \mathbf{O}_{\mathbf{3}}$ & $\mathbf{F e}_{\mathbf{2}} \mathbf{O}_{\mathbf{3}}$ & $\mathbf{\mathbf { T i O } _ { 2 }}$ \\
\hline Weight (\%) & 47.4 & 36.8 & 0.85 & 0.41 \\
\hline Composition & $\mathrm{CaO}$ & $\mathrm{MgO}$ & $\mathrm{K}_{2} \mathrm{O}$ & $\mathrm{Na}_{2} \mathrm{O}$ \\
\hline Weight (\%) & 0.03 & 0.18 & 1.42 & 0.07 \\
\hline
\end{tabular}

\subsection{Specimen Preparation}

Metakaolin Bangka and Metastar have a quite different texture. Metakaolin Bangka is dry and easy to fly while the Metastar is moist and stable. However, metakaolin Bangka is two times denser than Metastar. Therefore, these metakaolin cannot be activated by the same amount of activator. The ratio of $\mathrm{NaOH}$ and waterglass is 1:2 to reach dissolubility of $\mathrm{NaOH}$. The composition of both geopolymers shown in Table 2 .
Both geopolymer were prepared by mechanically mixing metakaolin and activator solution for 10 minutes. The slurry then casted into moulds and sealed. The prepared mixtures then cured at room temperature and $60^{\circ} \mathrm{C}$ for various curing time. At room temperature, the specimens were cured for 7 days, 14 days and 28 days. While at $60^{\circ} \mathrm{C}$, the specimens were cured for 4 hour, 12 hour and 24 hour, and cured for another 3 days before the mechanical strength test.

\subsection{Testing and Analysis Methods}

Compressive strength test of all specimens was prepared according to ASTM C109. Compression testing machine with loading rate of $60 \mathrm{kN} / \mathrm{min}$ was used to determine the compressive strength of specimens. The mould used for compressive test was $50 \times 50 \times 50 \mathrm{~mm}$. While the flexural strength and shrinkage of geopolymer measured using $200 \times 50 \times 50$ $\mathrm{mm}$ mould and $250 \times 25 \times 25 \mathrm{~mm}$ mould respectively.

\section{Results and Discussion}

\subsection{Results}

\subsubsection{Particle size distribution}

Measuring particle size while comparing two metakaolin is substantial as it help to understand metakaolin's surface area and reactivity. Smaller particle size means larger surface area. L.N Assi et al [8] found that smaller particle size lead to denser microstructure and enhance geopolymerization process. Larger surface area also increase the need of water, which can reduced the microcrack formation as less water available to evaporate. Nonetheless, increasing ammount of water will decrease the solid to liquid ratio, which was unwanted for compressive strength.

Figure 1 shows the particle size distribution of both metakaolins. As can be seen in Fig. 1 (a), Metastar has finer particle size as it has mean particle size at $3 \mu \mathrm{m}$ while the metakaolin Bangka as shown in Fig. 1 (b) has mean particle size at $5 \mu \mathrm{m}$.

Table 2. Composition of geopolymers.

\begin{tabular}{lll}
\hline Materials & MS (\%) & MB (\%) \\
\hline Metakaolin & 38.13 & 47.67 \\
\hline NaOH & 11.24 & 10.59 \\
\hline Waterglass & 22.49 & 21.18 \\
\hline Water & 28.11 & 20.54 \\
\hline
\end{tabular}




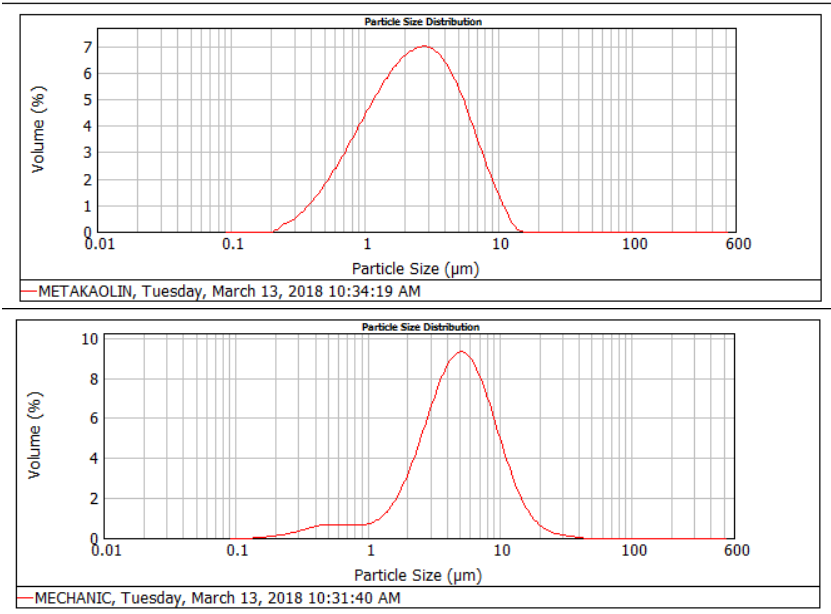

Fig. 1. Particle size distribution of (a) metastar and (b) metakaolin Bangka.

\subsubsection{Mechanichal strength}

The compressive strength of geopolymers was compared based on their curing temperature. Fig. 2 shows the compressive strength of both geopolymers at $60^{\circ} \mathrm{C}$ and room temperature through time. From Fig. 2, it can be observed that metakaolin Bangka based geopolymer has higher early strength in both curing temperature. Metakaolin bangka and Metastar both reach the highest strength at room temperature for 28 days $(22,14 \mathrm{MPa})$ and $(14,40 \mathrm{MPa})$.
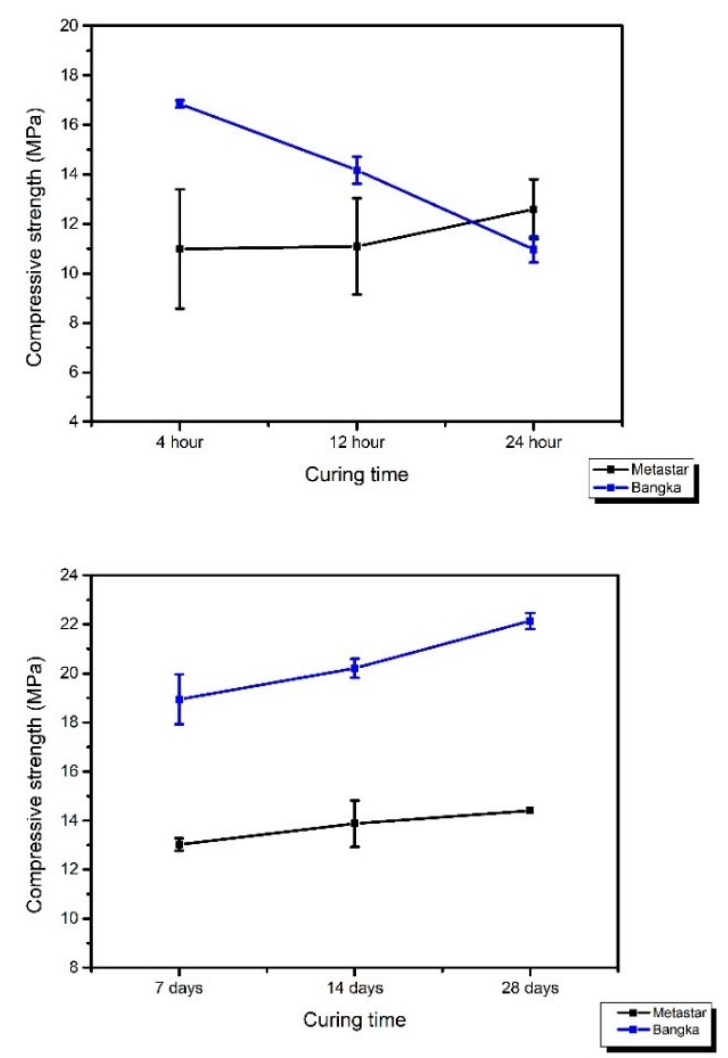

Fig 2. Compressive strength (a) at $60^{\circ} \mathrm{C}$ and (b) at room temperature.
Generally, geopolymer gain it's strength through time. But in Fig 2 (a) it can be seen that metakaolin Bangka based geopolymer's strength decreased as increasing of curing time, while the Metastar's strength is increasing. C.Y. Heah et al [9] found that at high temperature for long period of curing, reaction will be distorted, causing water evaporation and lead to formation of microcavities. It can be confirmed that at the end of curing for 24 hour, high ammount of pores were found at the top of specimen.

\subsubsection{SEM Observation}

Scanning electron microscopy was completed to observe the results of geopolymerization process. When geopolymerization occurred, metakaolin will lose its compactness and precipitation of sponge-like globular unit will be formed [10]. The reactivity of metakaolin can be determined by how much the amount of this precipitation formed.

From Figure 3, it can be confirmed that metakaolin Bangka has higher degree of reactivity. Figure 3 (a) and (b) shows the unreacted metakaolin (still compact structure) and few sponge-like globular unit. While figure 3 (b) and (c) shows less unreacted metakaolin and more sponge-like globular unit. This phenomenon can be explained by the TAM observation.

\subsubsection{TAM}

TAM (Thermal activity monitor) instrument was performed to monitor the heat flow when geopolymerization reaction occurred. Fig. 4 showed that both geopolymer undergone exothermic reaction, which release heat.

$X$. Yao et al [11] confirmed that peak of rate of heat flow $\left(Q^{*}\right)$ express the peak of geopolymerization reaction. Metastar reached its peak earlier than metakaolin Bangka lead to earlier flattened of $Q^{*}$ line of Metastar. Metastar also has higher total of heat flow (Q) than Metakaolin Bangka.

Higher heat flow and earlier flattened of Q* line indicated that the reaction occurred faster. Faster reaction doesn't always profitable. Too fast reaction causes higher amount of unreacted metakaolin, as shown in SEM observation. 

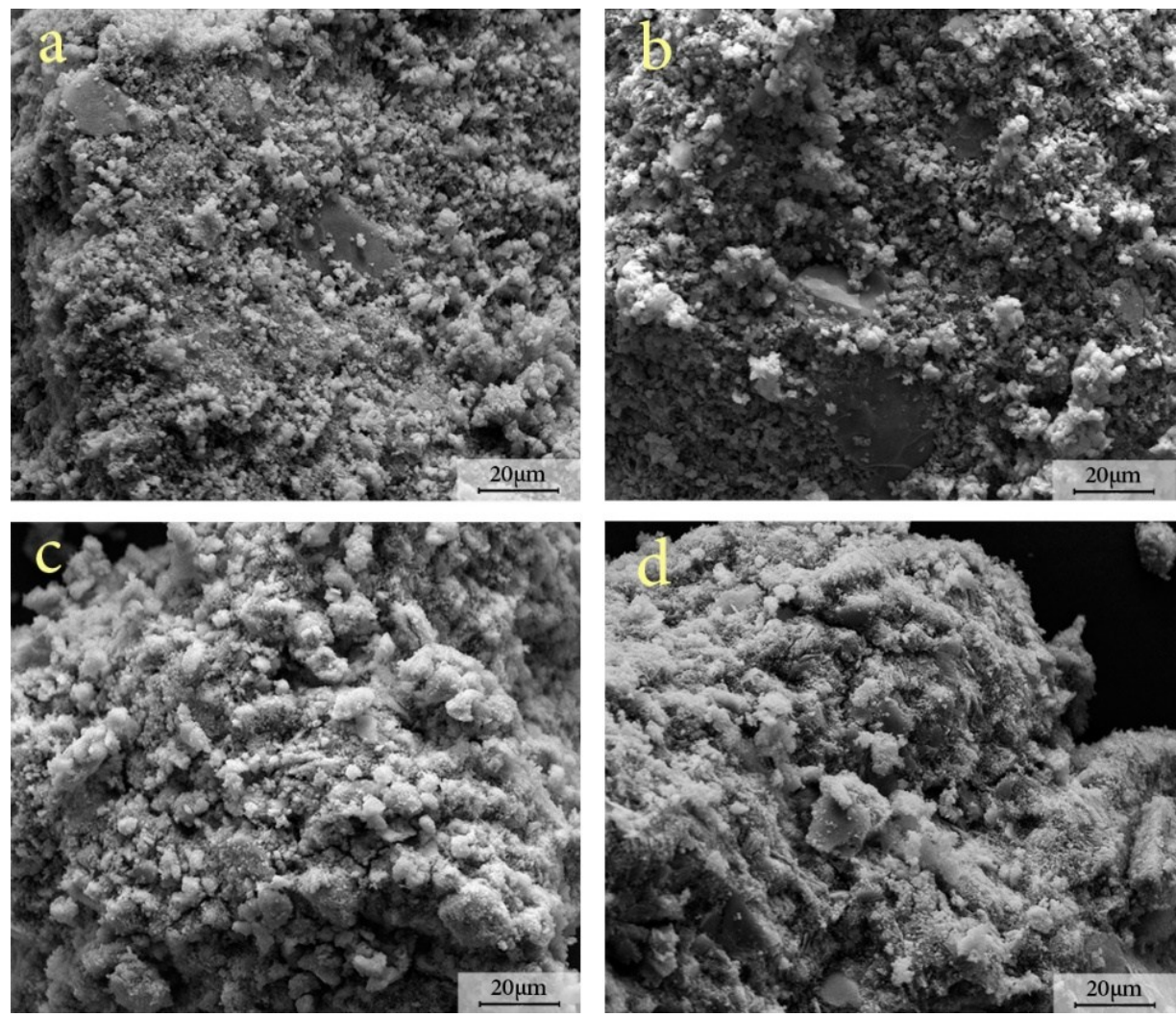

Fig. 3. SEM observation of geopolymer $60^{\circ} \mathrm{C}$ for 24 hours (a) Metastar, (c) Bangka, and room temperature for 28 days (b) Metastar, (d) Bangka.

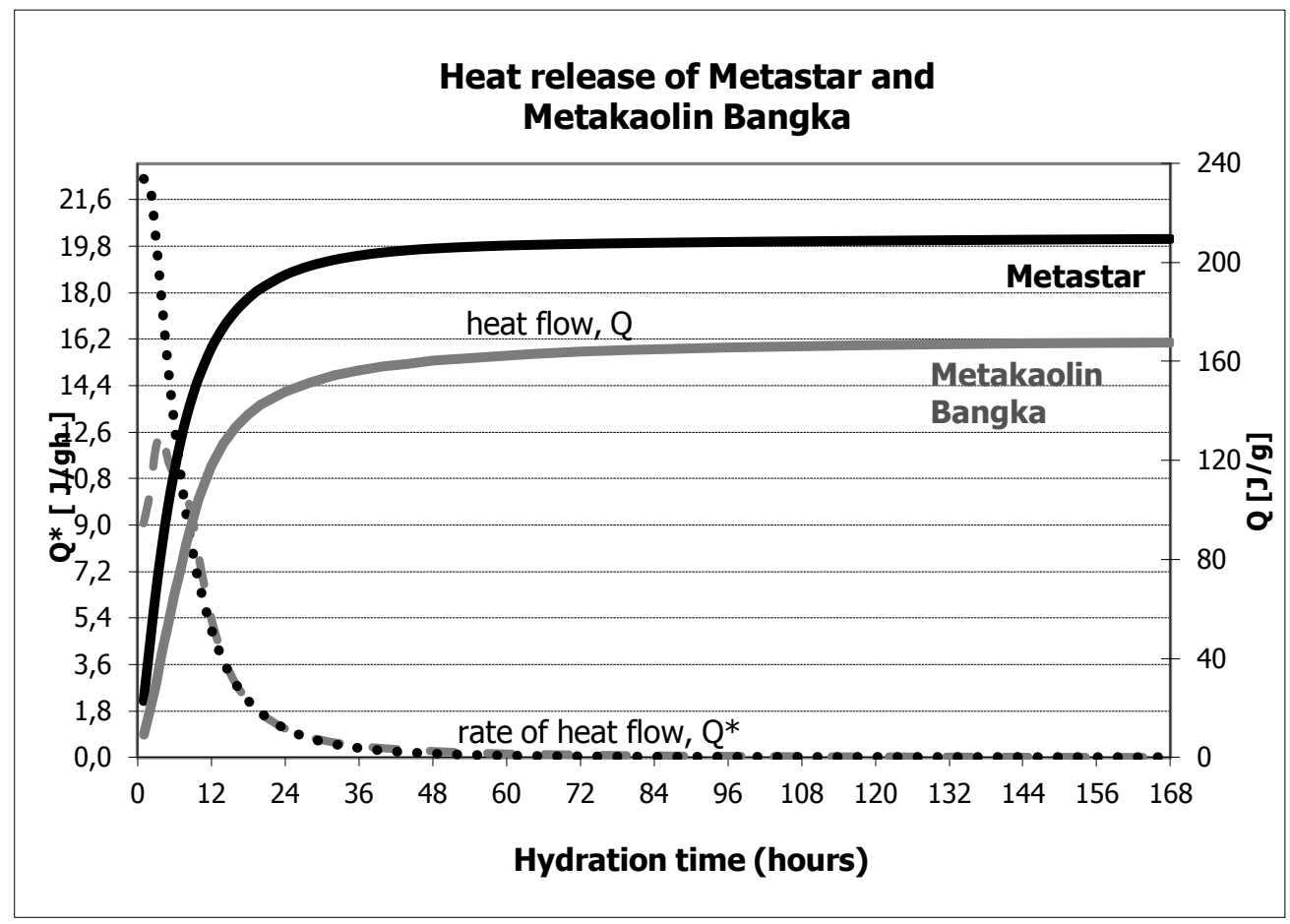

Fig. 4. TAM observation of Metastar and Metakaolin Bangka

*corresponding author. E-mail: zakiyuddin@metal.ui.ac.id, Tel. +62-21-7872350. 


\subsection{Discussion}

Aside from $60^{\circ} \mathrm{C}$ for 24 hours curing, metakaolin Bangka showed higher mechanical strength than Metastar at any time and temperature given. There were several factors accounted for this. One of the major factor was mix design. M. Lahoti et al [12] concluded that the most significant parameters affecting compressive stress was $\mathrm{Si} / \mathrm{Al}$ ratio, followed by $\mathrm{Al} / \mathrm{Na}, \mathrm{H}_{2} \mathrm{O} / \mathrm{Na}_{2} \mathrm{O}$ and water/solids. For starter, metakaolin Bangka has larger $\mathrm{Si} / \mathrm{Al}$ ratio of $(1,60)$ than Metastar $(1,53)$. As mentioned previously, despite both metakaolin cannot be mixed with the same amount of activator, $\mathrm{NaOH}$ to waterglass ratio added as activator were equal. Which means metakaolin Bangka had higher final $\mathrm{Si} / \mathrm{Al}$ ratio.

P. Duxon et al [13] made a study of how $\mathrm{Si} / \mathrm{Al}$ affect the compressive strength of a geopolymer. It turns out that compressive strength will increase with the increasing ratio of $\mathrm{Si} / \mathrm{Al}$ and reach its peak at 1,9. This was due to $\mathrm{Si}-\mathrm{O}-\mathrm{Si}$ linkage are stronger than $\mathrm{Si}-\mathrm{O}-$ $\mathrm{Al}$ and $\mathrm{Al}-\mathrm{O}-\mathrm{Al}$. It means, the higher the $\mathrm{Si} / \mathrm{Al}$ ratios will lead to higher compressive strength since the density of Si-O-Si bond increases. The further increasing of $\mathrm{Si} / \mathrm{Al}$ ratios after 1,9 would causes the decreasing of compressive strength. This due to the increasing of unreacted metakaolin.

Metastar has smaller particle size, so it needs more water in order to achieve good workability. This lead to the rising of water to solid ratio. Water is a fundamental component for geopolymer since water is the hydrolysis agent of $\mathrm{Al}^{3+}$ and $\mathrm{Si}^{4+}$. Z. Zuhua et al [14] discovered that during dissolution-hydrolysis periods, the higher liquid to solid ratios, the faster the reaction occurs. However, when reaching the polycondensation periods, the reaction change from consuming water (hydrolysis) to releasing water. Excess of water will hinder the polycondensation.

\section{Conclusion}

A comparative study of metakaolin Bangka and Metastar used as geopolymer's precursor has been conducted. It was found that metakaolin Bangka perform better mechanically and metallurgically. Metakaolin Bangka naturally has higher Si/Al ratio. Higher $\mathrm{Si} / \mathrm{Al}$ ratio lead to higher number of $\mathrm{Si}-\mathrm{O}-\mathrm{Si}$ bond and enhance compressive strength. Metastar has smaller particle size, causing it needs more water that hinder polycondensation and lower geopolymer strength. Metakaolin Bangka could already be used as precursor of geopolymer. Thus, the value of kaolin
Bangka can be improved by transforming it as metakaolin.

This research was supported by University of Indonesia through Hibah Publikasi Internasional Terindeks untuk Tugas Akhir Mahasiswa (Hibah PITTA) program. (2535/UN2.R3.1/HKP.05.00/2018)

\section{References}

1. J. Davidovits, Geopolymer Chemistry and Applications. SaintQuentin, France: Institut Géopolymère. 6-8. (2015)

2. H. Mikulčić, J. J.Klemeš, , M. Vujanović , K. Urbaniec, \& N. Duić, Reducing greenhouse gasses emissions by fostering the deployment of alternative raw materials and energy sources in the cleaner cement manufacturing process. Journal of cleaner production, 136, 119-132. (2016)

3. B. Singh, G. Ishwarya, M. Gupta, \& S. K. Bhattacharyya, Geopolymer concrete: A review of some recent developments. Construction and building materials, 85, 78-90 (2015)

4. B. H. Mo, H. Zhu, X. M. Cui, Y. He, \& S. Y. Gong, Effect of curing temperature on geopolymerization of metakaolin-based geopolymers. Applied clay science, 99, 144-148. (2014)

5. P. Rovnaník, Effect of curing temperature on the development of hard structure of metakaolin-based geopolymer. Construction and Building Materials, 24(7), 1176-1183. (2010)

6. Kementrian Energi dan Sumber Daya Mineral. Excecutive Summary Pemutakhiran Data dan Neraca Sumber Daya Mineral Status 2016. Badan Geologi ESDM. (2016).

7. G. Varga, The structure of kaolinite and metakaolinite. Epitoanyag, 59(1), 6-9. (2007)

8. L. N.Assi, E. E. Deaver, \& P. Ziehl, Effect of source and particle size distribution on the mechanical and microstructural properties of fly Ash-Based geopolymer concrete. Construction and Building Materials, 167, 372-380. (2018)

9. C. Y. Heah, H. Kamarudin, A. M. Al Bakri, M. Binhussain, M. Luqman, I. K. Nizar, \& Y. M. Liew, Effect of curing profile on kaolin-based geopolymers. Physics Procedia, 22, 305-311. (2011)

10. Y. M. Liew, C. Y. Heah, \& H. Kamarudin,. Structure and properties of clay-based geopolymer cements: A review. Progress in Materials Science, 83, 595-629. (2016)

11.X.Yao, Z. Zhang, H. Zhu, \& Y. Chen, Geopolymerization process of alkali-metakaolinite 
characterized by isothermal calorimetry. Thermochimica Acta, 493(1-2), 49-54. (2009)

12. M. Lahoti, P. Narang, K. H. Tan, \& E. H.Yang, Mix design factors and strength prediction of metakaolin-based geopolymer. Ceramics International. (2017)

13. P. Duxson, J. L. Provis, G. C. Lukey, S. W. Mallicoat, W. M. Kriven, \& J. S. Van Deventer, Understanding the relationship between geopolymer composition, microstructure and mechanical properties. Colloids and Surfaces A: Physicochemical and Engineering Aspects, 269(1), 47-58. (2005)

14. Z. Zuhua, Y. Xiao, Z. Huajun, \& C. Yue,. Role of water in the synthesis of calcined kaolin-based geopolymer. Applied Clay Science, 43(2), 218-223. (2009) 